\title{
¿Empleadas de por vida? \\ Peruanas en el servicio doméstico de Barcelona ${ }^{1}$
}

\section{Ángeles Escrivá}

Plaza de Alicante, 4. 46600 Alzira (Valencia). Spain

aescriva@hotmail.com

\section{Resumen}

Las peruanas que llegan a Barcelona durante la década de los noventa se insertan principalmente como empleadas domésticas, a pesar de que no solían ejercer esta actividad laboral en su país de origen y cuentan con medios y altos niveles de instrucción. Las razones de la emigración, el modo cómo se produce y el contexto de llegada determinan esta inserción. Sin embargo, el proyecto que inicialmente se planeó como temporal se convierte a menudo en permanente, al verse continuamente prolongado. Se comprueba de esta manera que nos hallamos, por una parte, con una perpetuación de las peruanas en el servicio doméstico, por otra parte, ante la etnización del sector de empleadas de hogar, integrado ahora mayormente por mujeres de ciertas procedencias extranjeras. Estos dos hechos se producen bajo el fenómeno migratorio transnacional, impactando de diversos modos en las inmigrantes y sus familias.

Palabras clave: inserción laboral, cuidado de ancianos, transnacionalismo, permanencia.

Abstract. Domestic for life? Peruvian women in the Barcelona domestic help sector

Those Peruvian women who arrive to Barcelona during the nineties work mainly as domestic helpers, though they did not use to do that job in their country of origin and have medium and high levels of education. The reasons for migrating, the way how is done and the context of arrival determine their labour market insertion. However, the project which was initially planned as temporary becomes often permanent because it is continually prolonged. Therefore, it is obvious that, on one hand, there is a perpetuation of Peruvian women in the domestic service and, on the other hand, an ethnification of the sector, composed now to a large extend by women from specific foreign origins. Both facts occur under the transnational migratory phenomenon, having a diverse impact on migrant women and their families.

Key words: labour insertion, care of the elderly, transnationalism, permanence.

1. Quisiera agradecer a Julia Tavares y Tatiana Sikoska, Social Affairs Officers del United Nations International Research and Training Institute for the Advancement of Women (INSTRAW) en Santo Domingo (República Dominicana), así como a Natalia Ribas, por revisar repetidamente la redacción de este artículo y hacer sugerentes comentarios. El resultado del mismo es, sin embargo, absoluta responsabilidad de la autora. 


\section{Sumario}
1. Introducción
4. En conclusión: ¿empleadas de por vida?
2. ¿Por qué emigran las peruanas?
Bibliografía

3. ¿Cómo se insertan sociolaboralmente

las inmigrantes peruanas?

\section{Introducción}

Desde hace alrededor de tres décadas la emigración internacional femenina ha pasado a tener una especial relevancia. La globalización económica con la expansión del capitalismo y el industrialismo a prácticamente todas las regiones mundiales ha venido acompañada por una proliferación de los medios de comunicación de masas - con el correspondiente impacto cultural e informativo-y la mejora del transporte, haciendo más evidentes si cabe los contrastes socioeconómicos. De estos cambios han estado participando más activamente las mujeres, accediendo ahora a la emigración laboral interna e internacional como alternativa a las desfavorables condiciones económicas y sociales que se les presentan en sus lugares de origen. La más reciente emigración femenina es, en gran medida, una emigración laboral, generalmente con planteamientos temporales, y autónoma, en el sentido que no está motivada por procesos de reagrupación familiar con anteriores cónyuges emigrantes masculinos o sus progenitores, sobre todo en América Latina y en el sudeste asiático (UN, 1997). Sin embargo, el hecho que se trate de una emigración autónoma no significa que no esté condicionada por otras personas, miembros familiares dependientes de las mujeres y sus parientes con autoridad sobre ellas, y por las personas integrantes de las redes migratorias que les ayudarán a llevar a cabo la emigración y el asentamiento en la nueva sociedad receptora.

A pesar de que se ha estado tratando más prolíficamente la nueva participación de las mujeres en las migraciones, la literatura internacional aún recoge insuficientemente cuestiones relacionadas con las características laborales de estas emigrantes. Se ha investigado - y dicho poco por tanto- sobre el hecho de que las mujeres migrantes se inserten abrumadoramente en segmentos laborales etnificados y sexualmente diferenciados; que en muchos casos padezcan un proceso inicial de descualificación con la emigración, al haber tenido una experiencia previa de mayor nivel laboral o educacional y que se mantengan en estos sectores durante períodos cada vez más prolongados. La situación de las mujeres en conjunto se muestra algo diferente respecto a la de los hombres. Por ejemplo, los datos sobre la emigración internacional desde Sri Lanka demuestran que las emigrantes suelen insertarse en sectores laborales menos cualificados — sea cual fuere su cualificación previa - que sus compatriotas hombres (Brochmann, 1993). También los estudios sobre la migración filipina - con rasgos similares a la peruana, como veremos inmediatamente- nos hablan de esa presencia de las licenciadas asiáticas en el servicio doméstico internacional (Barsotti y Lecchini, 1995). 
Aprovechando el material recogido durante una investigación que llevé a cabo hace un par de años ${ }^{2}$, me propongo demostrar en este artículo que la inserción y el mantenimiento de las peruanas en el servicio doméstico de Barcelona ${ }^{3}$ es producto de unas condiciones de partida y de llegada impregnadas de la experiencia transnacional migratoria. Esto quiere decir que las mujeres, aparte de las constricciones a las que se enfrentan en la sociedad receptora, mantienen una estrecha ligazón con la realidad en origen que les condiciona excepcionalmente a optar por unos y no otros caminos.

Por último, el mantenimiento en el servicio doméstico tiene para estas mujeres y sus familias consecuencias en el plano económico y social, las cuales son percibidas más o menos positivamente, dependiendo en gran parte del grado de sorpresa con que se presenten. Es decir, consecuencias negativas esperadas son mejor llevadas o soportadas por las mujeres y sus familias, por cuanto se contemplan como signos de un sacrificio libremente elegido.

\section{2. ¿Por qué emigran las peruanas?}

La emigración laboral de peruanas tiene sus antecedentes en las migraciones internas que tuvieron lugar en el país durante buena parte del siglo XX. Las mujeres han tenido un papel preponderante en los movimientos poblacionales del campo a la ciudad, representando el 50,6 y el $51,2 \%$ de toda la emigración peruana rural-urbana para la década de los sesenta y los setenta respectivamente (Instraw, 1994: 27). Ellas se insertaron predominantemente como domésticas en las casas de familias urbanas acomodadas. Jelin (1978) revela por aquellas fechas que las únicas alternativas laborales disponibles para estas mujeres se encontraban en el servicio doméstico, migrando en muchos casos no por el atractivo de un empleo retribuido, sino por ser el único modo

2. La investigación de la que hablamos se tituló: «Peruanas en el servicio doméstico de Barcelona. Trayectorias socio-laborales». Tuvo lugar entre los años 95-97 y la mayor parte de este tiempo estuvo becada por la Comisión Europea en el European Research Centre on Migration and Ethnic Relations (ERCOMER) de la Universidad de Utrecht, en los Países Bajos. El trabajo de campo se dividió entre Barcelona (95 y parte del 96) y Perú (parte del 96 y parte del 97) y contó además con la doble supervisión desde Utrecht de la Dra. Helma Lutz y desde Barcelona de la Dra. Carlota Solé.

3. La migración laboral peruana en Barcelona tiene un elevado componente femenino. Los datos estadísticos para el año 97 nos presentan porcentajes del 64\% aproximadamente (CIE, 1998). Con el mayor acceso de las mujeres a la emigración autónoma han ido consolidando redes compuestas de vecinas, amigas y familiares, impulsando por tanto una emigración mayoritaria de mujeres. Estas mujeres suelen ser solteras, jóvenes, con o sin hijos, aunque también se encuentran casadas/convivientes cuya emigración suele reportar muchos trastornos en la relación con sus parejas. Varía así mismo el nivel educacional y la experiencia profesional entre las emigradas. No obstante, llama la atención en el caso peruano - como ocurre entre las filipinas - el elevado grado de estudios de muchas empleadas domésticas, habiendo incluso trabajado por algunos años en su país, cesando o jubilándose de maestras, enfermeras, secretarias, y otras profesiones con baja retribución, para emigrar y desempeñar diferentes trabajos en otros países (Escrivá, 1997). 
de asegurar el sustento y el cobijo ${ }^{4}$. Para ser criadas, estas mujeres debían ser preferiblemente solteras y sin hijos, puesto que las condiciones de trabajo como internas no permitían desempeñar una doble jornada. Con el tiempo, sin embargo, se entendía que la muchacha se casaba y debía dejar el trabajo como interna pasando a trabajar como empleada externa, o a insertarse en otros sectores o labores a cuenta propia típicamente femeninas (la costura, el trabajo industrial a domicilio o la venta ambulante, principalmente).

Es en la década de los años ochenta cuando se inaugura el éxodo autónomo de mujeres hacia otros países, primero de la región, como Venezuela o Argentina, incluso Estados Unidos, y poco más tarde hacia otros continentes: en Europa destacan Italia y España ${ }^{5}$, y en Asia, Japón (Altamirano, 1996). En un principio son las élites y clases medio-altas las que emigran motivadas por la crisis económica y la inseguridad social y política. Estas élites conseguirán insertarse en mejores condiciones económicas y sociales que quienes les sigan posteriormente. A finales de los ochenta y sobre todo a principios de los noventa emigra un gran número de ex empleados y empleadas del Estado, quienes sufrieron las consecuencias de la congelación de los salarios y la reducción de los puestos vía las jubilaciones anticipadas o los despidos masivos dictaminados por la política económica de Fujimori ${ }^{6}$. En fechas posteriores, existen evidencias de que se han unido al flujo ex estudiantes y personas provenientes de los estratos económicos más modestos del Perú.

Entre las peruanas entrevistadas en Barcelona ${ }^{7}$, se comprobó que partían de una situación de desempleo y subempleo generalizado en su país de origen,

4. El sistema se rige por la institución de las «madrinas», que acogen a las campesinas niñas y adolescentes en sus casas de la ciudad a cambio de que trabajen gratuitamente como domésticas.

5. Según Altamirano (1996: 116), en 1993 España tenía 45.000 e Italia 25.000 inmigrantes peruanos y peruanas. Razones históricas y culturales (colonización e inmigración europea), además de las características de los mercados de trabajo receptores y las (inexistentes) políticas de inmigración de los años ochenta, explican la elección de estos destinos mayoritarios. La Iglesia católica, en particular en Italia y España, además de proveer los soportes sociales y psicológicos, es un facilitador para encontrar trabajo, además de brindar alimentos gratuitos a las personas indocumentadas y las desempleadas, en particular a muchos peruanos y peruanas que llegaron en los últimos años (ibídem: 76). Sin embargo, el autor apunta —de manera sorprendente puesto que carece de estudios que avalen tal apreciación- que «en comparación al trato que dan los españoles y alemanes, en general, los italianos son más tolerantes; además, las instituciones se muestran más caritativas y comprensibles con los problemas de los inmigrantes» (ibídem: 139).

6. Quien, no olvidemos, no hizo sino seguir los dictámenes del Fondo Monetario Internacional estableciendo un estricto plan de ajuste estructural. También Ribas (1994) destaca este factor de expulsión en la emigración de profesoras filipinas hacia España.

7. Fueron recogidos 32 relatos de vida de mujeres peruanas, abarcando una amplia gama de circunstancias sociales y familiares. Adicionalmente, el estudio cualitativo estuvo acompañado por la revisión de datos aportados por el Consulado Peruano (sobre unas 700 personas) y una de las casas religiosas mediadoras en la contratación de domésticas en Barcelona (sobre otras 300 mujeres). También fue crucial en la investigación la toma de datos a partir de numerosas entrevistas informales con inmigrantes y observación participante en una asociación de mujeres peruanas en Barcelona. 
en donde la crisis económica y las medidas tomadas encaminadas a su superación habían comportado - como dijimos- el congelamiento de los salarios, el despido o la jubilación anticipada de muchos cargos públicos (profesoras, enfermeras, funcionarias...), y el encarecimiento de la vida paralelamente al aumento de las necesidades económicas por la privatización de muchos servicios antes prestados por el Estado, como la salud y la educación, lo cual afectó especialmente a las mujeres (Tanski, 1994).

Razones de tipo macroeconómico o estructural explicarían, en principio, el éxodo de peruanos hacia el exterior. Pero ¿por qué en concreto las mujeres? y ¿por qué eligieron esos destinos y esas actividades? Para entender estos tres hechos nos sirve la teoría de la estrategia doméstica de supervivencia, la cual acentúa la importancia del grupo doméstico en la selectividad por sexo y la decisión migratoria ${ }^{8}$, y el análisis de las redes migratorias.

La posición y el rol de las mujeres dentro de la familia es un determinante crítico de la emigración femenina, como han dado en señalar las investigadoras como Lim (1998). Aunque la familia también ejerce su influencia sobre la migración masculina, su consideración con respecto a la migración femenina es esencial. Es dentro de la familia donde mejor se manifiesta la subordinación de las mujeres a la autoridad masculina; es la familia quien asigna o define los roles para las mujeres a partir de los condicionantes sociales y culturales, la que a cambio determina sus motivaciones relativas e incentiva la emigración; y es la familia la que provee de los recursos y la información que puede apoyar o desincentivar la emigración. Esta dinámica intrafamiliar, jerárquica en términos de sexo y edad, que condiciona la emigración femenina, se refleja en la historia de muchas emigrantes, entre ellas Judy Edith, una peruana que fue "obligada», literalmente, por su hermano mayor a emigrar a España dejando a su único hijo a cargo de la familia? . Hillman (1996) resume en su

8. La estrategia doméstica de supervivencia se ha convertido en una potente herramienta explicativa, viniendo a complementar los análisis anteriores: primero, el nivel individual de análisis tuvo su época de mayor florecimiento en la teoría de la elección racional modernizadora; segundo, el nivel social global presentó su mayor esplendor en los análisis postmarxistas estructurales. Como ha señalado Lyckama à Nijeholt (1995: 55), quizás la mejor solución es integrar las tres perspectivas de estudio con sus diferentes niveles de análisis, aunque teniendo cada una diferente importancia: «In order to understand the labour migration process, it is important, in my view, to stay embedded in the historical-structural approach and consider the structural factors as the forces which bring about migration. Within those parameters, the individual decision to migrate should be perceived as being strongly influenced by collective considerations within the social network of family, household, kin, and community, as well as by the outcome of conflicts of interest within that network».

9. Este ejemplo nos refiere al caso frecuente en Perú de jóvenes madres solteras que viven en la casa familiar bajo la autoridad del padre de familia o, en su defecto, del hermano mayor, quien viene a tomar el papel de autoridad principal. Judy Edith ya tenía una hermana emigrada a España y, por tanto, su hermano decidió que para mejorar la situación económica de toda la familia y poder ofrecerle un mejor futuro a su hijo - así como para apartarla del hombre con quien había tenido el pequeño - tenía que emigrar también. Ella se resistió a marchar pero el hermano insistió y los demás miembros familiares apoyaron la idea. 
estudio ubicado en el servicio doméstico de Milán, Italia, dos tipos de razones principales para la emigración peruana femenina ocurrida a principios de los noventa ${ }^{10}$, ambas condicionadas más o menos intensamente por el grupo doméstico: a) la necesidad de supervivencia familiar, y $b$ ) el deseo de mantener e incluso elevar el nivel de vida/consumo individual y familiar.

La supervivencia familiar ha ido recayendo más y más sobre las mujeres, puesto que la crisis económica ha golpeado duramente el empleo masculino. Con ello, mujeres que antes no trabajaban fuera de la casa tuvieron que salir a resolver las demandas familiares aparte de las domésticas, y las que ya trabajaban tuvieron que ver el modo de incrementar los ingresos, igual o más que los hombres, con el pluriempleo a base de pequeños y esporádicos trabajos adicionales. Pero también tiene especial peso en el caso latinoamericano el elevado número de familias monomarentales o encabezadas por mujeres ${ }^{11}$. Más aún, las demandas de empleo femenino han ido en aumento de modo paralelo al crecimiento de los niveles de instrucción de las mujeres. Muchas desean trabajar y ganar suficiente para mantener a sus familias, con o sin la ayuda del miembro masculino. En el caso de que haya este miembro masculino que contribuya, las mujeres se otorgan la tarea de elevar el nivel de vida/consumo familiar y suyo individual ${ }^{12}$.

Por otro lado, aparte de los desequilibrios económicos entre unas y otras áreas, y las estrategias que se utilizan para superarlos, el establecimiento de comunidades que se amplían con el funcionamiento de las redes tiene un papel fundamental en la existencia y mantenimiento de los flujos femeninos ${ }^{13}$. Las redes

10. Otra contribución es la de Pérez (1997: 138), quien distingue entre la inmigración peruana de los noventa en España tres tipos principales de orígenes sociales y por tanto necesidades: a) la clase baja, minoritaria, quien utiliza una clara estrategia de sobrevivencia; b) la clase media en regresión, mayoritaria, combinando la estrategia de la sobrevivencia con la del ascenso social; c) la clase media aspirante, también minoritaria, que pretende cualificarse e incluso integrarse a medios y altos niveles ocupacionales en España.

11. Oso (1998: 239) distingue entre jefaturas de hogar de hecho y de derecho. Las primeras son especialmente numerosas en el contexto peruano, en donde los hombres a menudo no han podido o no han querido hacerse cargo del mantenimiento de sus descendientes, pasando a ser exclusiva obligación de las madres y de los hijos e hijas mayores del grupo doméstico.

12. Para aquéllas que carecen de obligaciones familiares apremiantes, porque están solteras y/o tienen familias relativamente acomodadas, el deseo de mayor autonomía personal y a la vez de mayor poder y decisión sobre los asuntos familiares es fundamental. La emigración se convierte entonces para estas mujeres en una vía hacia la elevación de su estatus personal, su empoderamiento, y su autorrealización. El mimetismo social, producto de la moda por viajar al extranjero, conocer otros lugares, encontrar una pareja afuera más deseable, o simplemente la fascinación y el engaño son otros motivos que generalmente se entrecruzan con los anteriores.

13. Existen redes migratorias femeninas o altamente feminizadas operando con mayor o menor eficacia según los casos. Un conocido caso es el de las mujeres filipinas, quienes han sido una de las migraciones femeninas más antiguas y organizadas dirigidas hacia un amplio abasto geográfico: Norteamérica, Europa, Asia y Oceanía (Ribas, 1994). Como presentamos anteriormente, la emigración peruana también se encuentra notablemente feminizada, debido en gran medida al actuar de las redes integradas mayormente por mujeres. La elección 
son, como han señalado Gurak y Caces (1992), canales por los que transita la información, el apoyo moral y emocional y los recursos materiales necesarios para posibilitar la afluencia de otros migrantes, su inserción en el nuevo contexto y a la vez su participación en el continuado mantenimiento de la red. Con ello las redes crean facilidades pero también obligaciones y constricciones a los participantes y a las participantes. Dentro de ellas circulan informaciones verídicas pero también rumores y farsas. Por lo tanto, no toda la información transmitida por estos canales favorece a los migrantes, sino que puede tener una influencia perversa ${ }^{14}$.

Además, muchas de las redes migratorias actuales se han ido «formalizando» a medida que los gobiernos de los países receptores han dificultado el ingreso a su territorio a nuevos inmigrantes. Se han constituido agencias, más o menos legales, a partir de antiguos inmigrantes y nacionales que perciben sustanciosos ingresos con el tráfico (a menudo concebido como "acompañamiento») de personas ${ }^{15}$. Con ello se evidencia que las restricciones a la inmigración, por una parte, abocan a las migrantes a una mayor vulnerabilidad al tráfico y a la violencia sobre ellas, por otra parte, están limitando el retorno con la limitación a las entradas y salidas, en un contexto en el que las adversas condiciones de partida que incentivan la emigración y desaconsejan el retorno siguen quedando intactas.

\section{3. ¿Cómo se insertan sociolaboralmente las inmigrantes peruanas?}

La inmigración peruana en Barcelona se ha convertido en pocos años en la presencia extracomunitaria más numerosa después de la marroquí (CIDOB, 1998). Se encuentra notablemente feminizada $(65 \%)$ y presenta una elevada ten-

de los destinos migratorios viene dada en buena parte por el uso de estas redes migratorias establecidas que proporcionan información y apoyo hacia algunos lugares concretos y no otros. Son los miembros más arriesgados quienes se encargan de explorar otros posibles mercados e inaugurar nuevos movimientos de población inmigrante. Hay evidencias de extensas redes en las ciudades de Madrid y Barcelona. En esta última ciudad una buena parte de ellas provienen de la ciudad de Trujillo en el distrito norteño del Perú llamado La Libertad, además de las de procedencia limeña. Según comentarios de algunas de nuestras entrevistadas, en algún caso estas redes habían posibilitado la emigración de hasta más de treinta miembros de una misma familia.

14. Entre los casos estudiados de peruanas emigradas a Barcelona se halló que con frecuencia partían de su país sin tener un conocimiento exacto de las labores que realizarían en destino, porque sus informantes no gustaban de especificar. En lo referente a los sueldos, se especulaban cantidades alrededor de los 1.000 dólares mensuales, supuestamente de fácil obtención. Con el agravante de que, para llevar a cabo sus viajes, las mujeres se habían endeudado considerablemente y tenían obligaciones económicas para con distintos miembros de su familia: hijos, esposo, padres, hermanos, en cuanto a envío de remesas.

15. Los variados servicios que prestan estas agencias suelen venir acompañados de numerosas irregularidades como: el cobro excesivo de tarifas, el engaño en las expectativas, el abandono en los países intermedios, el ocultamiento de intenciones, el maltrato físico y psicológico, la falsificación de documentos y dinero, el incumplimiento de las leyes de extranjería de los países destinatarios, etc. 
dencia a la actividad laboral, o sea que no es producto básicamente de la reagrupación familiar con sus cónyuges masculinos. Dentro del conjunto español, Barcelona es la segunda ciudad con mayor número de residentes peruanas después de Madrid (inmigración estudiada por Tornos y otros, 1997, y Pérez, 1997), presentando unos rasgos demográficos y sociolaborales muy similares en ambos casos.

Una vez aterrizadas en Barcelona, las peruanas entrevistadas manifestaron en general haber quedado sorprendidas por las condiciones tan "avanzadas» de la ciudad en términos de orden y eficacia de los servicios; a la vez que desencantadas al poco tiempo por las condiciones tan adversas para ellas, como son la discriminación social de la que algunas se sienten objeto, la escasez de trabajos bien pagados (respecto a los 1.000 dólares de referencia) y/o cualificados, el alto costo de la vida como de los alquileres, etc. En las entrevistas se evidenció que no tenían en general experiencia laboral en el sector del servicio doméstico - al cual mayoritariamente accedían por medio de las redes_-, lo consideraban un cuasi trabajo con bajo reconocimiento social y salarial y distaba de sus expectativas laborales dadas sus cualificaciones ${ }^{16}$.

En destino son varios los factores condicionantes de la situación de las mujeres inmigrantes. El mercado de trabajo es el elemento central y en torno a él se configuran las políticas migratorias, de control y de integración, más los climas sociales generales y locales de aceptación o rechazo hacia la presencia extranjera.

Las teorías han descrito la inserción de los trabajadores y las trabajadoras migrantes en los mercados de trabajo de los países industriales avanzados en términos de segmentación (Piore, 1975). Significa que para la gran mayoría de inmigrantes las oportunidades laborales se presentan sólo en aquellos empleos menos deseados por los nacionales, porque están peor pagados, son duros, sucios, inestables, estacionales, inseguros o aislantes. Un desarrollo de la teoría de la segmentación del mercado laboral habla de un mercado de trabajo primario y otro secundario, que a su vez están subdivididos, siendo las mujeres y sobre todo los inmigrantes y las inmigrantes quienes se colocan en los peores puestos, en términos de prestigio social, por ejemplo. Las mujeres inmigrantes quedarían relegadas a los empleos específicamente femeninos.

Por esto la mayor parte de peruanas emigradas a Barcelona desde finales de los años ochenta y sobre todo durante los noventa se han insertado laboralmente en el servicio doméstico, incluyendo dentro de sí el cuidado de niños, enfermos y ancianos. Esto es así por cuanto ésta es la actividad que más número de mujeres extranjeras demanda, ya que las españolas no desean ejercerla y requieren cada vez en mayor número de estos servicios que no son compartidos con los hombres ni resueltos por las provisiones de las políticas de bienes-

16. Según los datos recogidos en el Consulado y la Parroquia en 1995-96, la mayoría de peruanas inscritas habían finalizado al menos estudios secundarios e iniciado algún estudio superior, mientras que el número de licenciadas y profesionales experimentadas, sobre todo en los campos del magisterio y la enfermería, también era muy significativo. 
tar. Se han dado paralelamente dos tipos de fenómenos: por un lado, la creciente participación laboral de las mujeres autóctonas y su deseo de desligarse en mayor medida de las labores del hogar; por otro, la elevación de la esperanza de vida de la población adulta y la reducción en tamaño de los núcleos familiares, con el consiguiente aumento del requerimiento de servicios personales de atención y cuidado, tanto a personas que viven prácticamente solas como a familias.

El cuidado de ancianos — verdadera área de especialización de las peruanas-, aunque es una de las actividades más valoradas y reconocidas salarialmente dentro del sector, comporta mayor estrés, por la precariedad psíquica y motriz de muchos ancianos y ancianas, e inseguridad laboral, puesto que la dedicación a un anciano se limita a los pocos años, meses de vida que pueda tener desde que se contrata el personal auxiliar ${ }^{17}$. Atender a estas personas requiere una disponibilidad absoluta durante todos los días de la semana y todas las horas del día, quedando muchas mujeres así relegadas al hogar del empleador o de la empleadora durante largas temporadas. El régimen laboral más común entre las entrevistadas de llegada más reciente era por tanto el de internas, debido en gran parte a las necesidades de asistencia continuada a las personas que cuidan.

Adicionalmente, el régimen de empleadas de hogar dentro de la Seguridad Social española se encuentra en inferioridad de condiciones respecto a otros regímenes y, por tanto, relega a las inmigrantes a condiciones de ciudadanas de segunda categoría (sin seguro de desempleo, por ejemplo). Peor aún cuando las mujeres se encuentran en irregularidad documentaria, porque en ese caso están mayormente expuestas a todo tipo de abusos y discriminación por parte de sus empleadores y quienes trafican y se benefician de ellas (agencias colocadoras, etc.), como la falta de pago por vacaciones, seguro social, despido sin causa justificada, cobro de tasas por colocación, etc.

Sin embargo, los episodios de desencuentro con empleadores y agencias no abundaron en los relatos de las mujeres y sí los halagos respecto al buen trato de mucha gente en su casa y en la calle. En lo referente a los procesos de documentación, las peruanas han asistido a una mejora de su situación legal paulatina por medio de su inserción laboral como empleadas de hogar, lo que les ha llevado a presentar una mejor inserción social que otras y otros extranjeros. El recurso a la petición de la doble nacionalidad y a la reagrupación familiar de esposos, padres e hijos, estaba en la mente de muchas y los datos más actuales lo corroboran. También dentro del sector muchas mujeres manifiestan su preferencia por las labores de cuidadoras de ancianos que las de

17. Durante el estudio se comprobó que es más corta la permanencia laboral de las mujeres en sus puestos como domésticas cuidadoras de ancianos, sobre todo enfermos, que como domésticas centradas en labores de limpieza, cocina y cuidado de niños. Esto se debe a que en el primer caso la contratación se lleva a cabo generalmente cuando el anciano o la anciana llega a una situación en la que ya le es difícil atenderse solo o por alguno de sus hijos o hijas (parálisis parcial o total, demencia senil, etc.). 
simple personal de limpieza. La socialización genéricamente marcada de la que fueron objeto en su país les ha preparado para hacerse cargo de esos trabajos, que en origen seguramente deberían hacer igualmente pero de manera gratuita. Para una enfermera o profesora cuidar de una persona no es asunto tan ajeno a sus carreras profesionales y así es visto y explicado a los familiares en origen.

En cuanto al clima de aceptación social, existe en el caso de las peruanas - así como entre todas las trabajadoras del sector doméstico- una invisibilidad que las defiende contra la exposición de las amenazas y actos violentos de la calle. Esta invisibilidad se evidencia en el escaso eco social que tiene la numerosa presencia doméstica extranjera, en comparación con el alto grado de alarma que despierta la presencia inmigrante masculina, supuestamente invasora del espacio público. Además, como los distintos estudios sobre actitudes hacia los inmigrantes y las inmigrantes han señalado, la comunidad latinoamericana recibe mejor aceptación en cualquier caso que la africana o caribeña (Díez, 1998) también en Barcelona. La inserción en el contexto social y cultural catalán no es vivida como un problema y suele producirse con mayor rapidez entre aquéllas que mantienen más estrecho contacto con la población autóctona que entre aquellas que se mantienen dentro del propio grupo étnico, sobre todo debido a la numerosa presencia familiar.

Sin embargo, aunque no de manera abierta, la violencia para las empleadas domésticas se presenta a menudo en el día a día del puesto de trabajo con la asignación de peores condiciones laborales y salariales que a las trabajadoras nacionales, con el desprecio y el autoritarismo por parte de los empleadores y empleadoras especialmente en los regímenes laborales internos, y con lo que es más, la imposibilidad para acceder a otros puestos más deseados y conformes con sus capacidades y expectativas fuera del servicio doméstico.

Esta falta de oportunidades laborales fuera del sector se respalda en tres argumentos principalmente: $a$ ) en que a las inmigrantes sólo se les permita trabajar legalmente (al menos al inicio) en este tipo de labores, y a que se les impongan trabas al ejercicio de su profesión, como la necesidad de convalidar sus títulos, a veces previo examen de conocimientos, $b$ ) en que la red y la comunidad inmigrada en la que está inserta la migrante sólo tiene acceso a este sector, teniendo poca accesibilidad a otros canales nativos de relaciones sociales que posibilitarían la entrada a otros trabajos, y $c$ ) en que el gran desempleo existente para los nacionales y las nacionales limita la opción (en términos de rechazo a la formación y a la contratación) para las inmigrantes de insertarse en empleos más cualificados y por tanto mejor retribuidos y considerados. Con todo, muchas mujeres siguen sintiéndose afortunadas por poder contar al menos con el trabajo en el servicio doméstico — dentro del cual pueden ir escalando hacia mejores hogares, labores más especializadas y horarios menos opresivos-, y poder vivir dentro de los patrones de consumo que desean, enviando remesas a sus familiares y ahorrando para un futuro mejor, a menudo incierto y cada vez más postergado. 


\section{En conclusión: ¿empleadas de por vida?}

Caracteriza, por tanto, a esta inmigración peruana el hecho de transformar en pocos años sus proyectos de retorno en asentamiento permanente. Esto queda patente en la más reciente tendencia hacia la reagrupación familiar en sentido extenso ${ }^{18}$. Cuando llegan los familiares a quienes se les enviaba las remesas, las necesidades de ahorro por parte de algunas inmigrantes disminuyen, puesto que cuentan con nueva fuerza laboral que contribuya económicamente. Para quienes hacen venir a sus familiares dependientes (hijos, hijas y padres ancianos principalmente) surgen nuevos y más costosos gastos ${ }^{19}$ que obligan a seguir trabajando como domésticas, aunque se suele buscar el régimen de trabajo externo para poder compaginar las obligaciones familiares con las del empleo. Como consecuencia, la inserción laboral en el servicio doméstico, que fue vista en un primer momento como una solución transitoria, pasa a ser la ocupación a más largo plazo aunque las condiciones de los empleos a los que acceden - como vimos anteriormente-con el tiempo cambien.

Entre la gran cantidad de mujeres entrevistadas (formal e informalmente) y de historias relatadas por segundas y terceras personas, conocemos la existencia de unas pocas peruanas que dedican parte de su jornada laboral al ejercicio de otras actividades fuera del servicio doméstico, y todavía menos quienes abandonaron el sector completamente. Tanto en el primer caso como en el segundo se encuentran aquéllas que se colocan en los llamados «negocios étnicos» ${ }^{20}$. Éstos forman parte de la dinámica del transnacionalismo haciendo mantener en el nuevo lugar de residencia elementos de la cultura y formas de vida de la sociedad de origen. La peluquería y la estética a mujeres únicamente del colectivo, la venta de productos originarios del país, pero también la restauración, las agencias de viaje, préstamo y envío, son algunas de estas opciones.

Es fundamental para entender la permanencia de las peruanas en Barcelona como empleadas del hogar la evocación frecuente a la realidad en origen. Se permanece en puestos de trabajo a menudo poco deseados pero mucho mejor pagados de lo que estarían si desempeñaran su profesión en origen:

[...] no sé, a veces te pones a pensar si estará bien el quedarte o estará bien irte, se extraña la familia, mis hermanos, pero luego te pones a pensar, y te vas

18. Incluyendo muchos otros parientes aparte de los descendientes, ascendientes y esposos, y por lo tanto, no queda registrada en las estadísticas oficiales y sólo es percibida a través de la investigación de campo cualitativa.

19. Por los diferenciales en el costo de la vida.

20. Cuando el número de trabajadores de un cierto colectivo étnico se amplía sustancialmente, aparecen las comunidades étnicas generalmente ligadas a ciertos tipos de actividades económicas, entre las que cobran especial importancia los negocios intra e interétnicos, como han señalado Portes et Rumbaut (1990). El servicio doméstico representaría un nicho laboral para las mujeres inmigrantes extracomunitarias, mientras que los restaurantes y bares por y para los propios miembros del colectivo inmigrante formarían parte de los llamados «negocios intraétnicos». 
a ir allá ¿y qué voy a hacer ahora? trabajo no tengo, me tengo que poner a buscar trabajo, pero yo ya tengo 37 , a partir de los 40 ya no puedo trabajar, cuesta mucho que consigas, particular tal vez, para ir a ganar menos de lo que ganas aquí, ¡porque realmente te pagan! o sea, que uno ya no sabe si encajas allí o no, es como que hubieras, nos ha pasado cuando hemos ido, llegas y ya no te acostumbras, las cosas son diferentes, la gente hace su vida como normal, y tú ya estás fuera y dices, ahora hasta que vuelves a entrar, cuesta (July, 37 años, soltera sin hijos, enfermera, dos años en Barcelona).

El diferencial salarial — como vimos al referirnos a las causas de la emigración- es una importante razón para el mantenimiento de las mujeres en el servicio doméstico. Este diferencial permite llevar una vida más desahogada, mayor consumo y de más calidad, ayudar a quienes están allá, asegurarse una pensión en el futuro mediante el pago a la Seguridad Social española, y otros tantos beneficios que conlleva la vida en una sociedad económicamente más avanzada. Pero, como apuntamos al hablar de los distintos tipos sociales de emigrantes peruanas, debemos distinguir aquéllas cuyo primer y principal objetivo es la supervivencia del grupo familiar, de las que están intentando elevar el consumo no básico y emular modos de vida modernos, elevando, por ende, su propio estatus individual y/o familiar. Mientras que para las primeras es obvio que el mantenimiento en el servicio doméstico no plantea ningún problema con sus objetivos iniciales — tan sólo se pasa del régimen interno al externo cuando se trae a la familia-, para las segundas el mantenimiento en el sector es vivido de una manera más traumatizante y se buscan fórmulas que permitan compaginar el trabajo por horas con algún estudio o trabajo en otra área, dentro o fuera del sector de los negocios étnicos, que finalmente facilite el acceso hacia la actividad deseada:

[...] yo también digo que no me voy a quedar todo el tiempo haciendo esto (trabajar como doméstica), bueno, entre regularizar mis papeles, ahora los tengo regularizados, a regularizar a mi hijo, un poco ahora, y puedo salir y hacer otra cosa que no sea, de momento quisiera montar una peluquería con una amiga que también, era un proyecto, todavía está en ver cuánto capital hay, ver de donde es, ¿̇no? si no poner eso poner cualquier otro negocio (Lucy, 32 años, viuda con un hijo, secretaria, cuatro años en Barcelona).

Lucy, mientras se decide a montar su peluquería, dedica parte de su tiempo a la venta de cosméticos y a estudiar idiomas en una academia, ya que trabajó en el sector turístico en su país y ve factible la posibilidad de volver a dedicarse a ello en España.

La situación de la mujer en el ciclo de vida, su experiencia laboral pasada, y su posición de dependencia respecto a otros miembros de la familia también afectan a la trayectoria laboral de la migrante en el nuevo contexto. Así, tenemos mujeres como Hilda, que por su mayor edad, trayectoria laboral dilatada y poco satisfactoria en Perú, y existencia de un hijo y padres dependientes rehusan a cambiar de actividad laboral: 
[...] no, es que también yo no aspiro a más porque como ya he trabajado mucho en mi vida y he trabajado en empresas, pues ahora cuidaré mis ancianos (y hará la limpieza, cocina, plancha, etc.), para el poco tiempo que trabajaré más, que no será mucho tampoco (Hilda, 44 años, separada con un hijo, secretaria, tres años en Barcelona).

Si el trabajo no ofrece la deseada movilidad social ascendente, al menos queda la posibilidad para las mujeres solteras más jóvenes y de mayor contacto social con autóctonos de conseguir una relación con un hombre "blanco", español o comunitario, que compense esta situación. Sin embargo, estas relaciones no se dan en todos los casos deseados (parece que la peruana no se ajusta tanto al modelo de mujer admirado por los hombres autóctonos), pueden no ser estables y/o recabar en más incapacidad para la mujer de salir del sector en el que estuvo enclavada si la pareja no tiene suficiente holgura económica y redes sociales de apoyo $^{21}$. Con todo, queda la imagen positiva de la emigración en el país de origen que eleva a la migrante, sobre todo si hace ostentación de su progreso material allá mostrando los símbolos de la llamada «superación y progreso»: marido de "raza» blanca, casa de materiales nobles, carro, ropa europea, acento gringo.

Los retornos se revelan escasos, tanto en el momento de las entrevistas como después - como se ha podido saber por los contactos personales con un buen número de las entrevistadas- Nunca se produjeron o si se hicieron fueron siempre postergados y con muchas posibilidades de volver a convertirse en nueva emigración. Dos peruanas retornadas entrevistadas en Trujillo (Perú) en 1996 manifestaron su intención de volver a emigrar a España en un futuro breve, de hecho una ya no ha podido conseguir visado y planea dirigirse hacia otro de los nuevos destinos migratorios de la región, Chile. Otra de nuestras entrevistadas que regresó a Perú a fines de 1996 para proseguir los estudios universitarios e intentar allí la inserción laboral volvió a emigrar a Barcelona a inicios de 1999, insertándose nuevamente como doméstica, aunque ahora por horas. También muchas familiares de las emigradas declararon en Perú estar planeando su pronta emigración aún a sabiendas del destino laboral que les espera a su llegada, puesto que no cuentan con otra alternativa para generar esos ingresos desde los contextos laborales en los que se encuentran ${ }^{22}$.

Por lo tanto, podemos concluir que es la realidad de la familia/hogar transnacional la que va remodelando el proyecto migratorio de temporal a permanente. Las «oportunidades de empleo que disponen» y su «poder social de

21. Eli, una de nuestras entrevistadas, 28 años, casada con español y madre de dos hijos (uno de ellos fruto de una anterior relación en Perú), debe trabajar como doméstica en régimen externo para sufragar los gastos de la casa, ya que su marido está en paro con frecuencia, presenta gran eventualidad y precariedad laboral e inestabilidad emocional. Su relación está muy deteriorada por esta causa.

22. Durante el trabajo de campo en Perú contacté con numerosas mujeres y hombres de la familia de las emigradas que ahora se encuentran ya acá. 
negociación» (es decir, el «nivel de aceptación por su parte de las condiciones de trabajo»), según términos de Cachón (1997), determinan la permanencia de las migrantes peruanas como empleadas domésticas. Las redes migratorias aseguran el flujo constante de mujeres y de algunos hombres hacia los segmentos laborales disponibles en las sociedades receptoras, como es especialmente el servicio doméstico, favoreciendo la etnización del sector, que siempre será nutrido de nuevas inmigrantes. Para acceder a otros puestos más cualificados tendrán que competir con la fuerza laboral femenina y masculina autóctona (sobre todo en el caso de las nacionalizadas), y para mantenerse y mejorar relativamente dentro del sector de empleadas de hogar tendrán que competir con las autóctonas y con mujeres de otras nacionalidades extracomunitarias que también desean acceder a estos empleos de manera creciente: dominicanas, marroquíes, filipinas, ecuatorianas, mayormente.

Cabe distinguir tres tipos de situaciones encontradas entre las ya asentadas: a) para algunas, sobre todo las que tienen necesidades económicas familiares más apremiantes, vienen de estratos sociales populares y/o se encuentran en un determinado ciclo de su vida, la perpetuación de las mujeres en sus puestos de trabajo como empleadas de hogar internas o externas; $b$ ) para otras hay un movimiento más o menos intenso de cambio de empleos dentro del sector de limpieza y cuidados personales hacia mejores condiciones laborales (salariales, humanas, etc.), con mayor tiempo libre para el ejercicio de otras actividades remuneradas o no (trabajos complementarios, atención a la familia, estudio, ocio), actividades que son el camino que puede hacer cambiar el destino laboral en un futuro; c) hay quienes dejan el servicio doméstico remunerado para ejercerlo de manera privada en el propio hogar ${ }^{23}$, por último $d$ ) para muy pocas se produce un paso total y absoluto hacia sectores laborales más valorizados. Como explica la única entrevistada que ejerce regularmente una profesión liberal, en este caso abogada especializada en temas de extranjería:

[...] porque la mayoría, el término medio de mujer que viene, son mujeres que tienen como mínimo la secundaria terminada y muchas chicas tienen una carrera profesional, y entonces claro, vienen porque en estos momentos por la situación de allí ganan poco y vienen aquí a ser empleadas de hogar, pero hay dos mentalidades, la que viene a hacer dinero y luego volver, inicialmente es eso, y luego la que viene, estar un tiempo trabajando en lo que sea y luego tratar de convalidarse y tal y trabajar en lo suyo, o sea, se plantean que toda la vida van a estar de chachas.

23. Se desconoce la importancia cuantitativa entre peruanas del paso de domésticas a amas de casa, es decir, a no activas (según la denominación estadística oficial), generalmente por matrimonio, maternidad y mejora de la situación económica familiar. No obstante, aparecieron un par de casos durante nuestras entrevistas de mujeres que se consideraban amas de casa, aunque se constataba que no habían dejado completamente de ejercer algún tipo de actividad remunerada como la costura o la artesania en el domicilio, la venta de cosméticos, entre otras. 
Podemos apreciar que el análisis de la entrevistada se realiza desde un punto de vista individualista, en donde las constricciones de los contextos emisor y receptor parecen no tener una influencia decisiva en las trayectorias de las migrantes, producto sin duda de las facilidades con las que ella misma se encontró al llegar: al haberlo hecho en un momento inmediatamente anterior al boom inmigratorio peruano (finales de los ochenta), proceder de clase social alta y étnicamente valorada, y haber tenido una vasta experiencia profesional en su país, a lo que cabe sumar su condición de esposa de ciudadano español. Por el contrario, hemos constatado en todo nuestro análisis aquí que ambos contextos, con sus factores constrictores y facilitadores, deben ser considerados.

\section{Bibliografía}

Altamirano, T. (1996). Migración. El fenómeno del siglo. Peruanos en Europa, Japón y Australia. Lima: Fondo editorial de la PUCP.

BARSOTTI, E.; LeCCHINI, L. (1995). «The experience of Filipino female migrants in Italy». En International Migration Policies and the Status of Female Migrants: Proceedings of the United Nations Expert Group Meeting on International Migration Policies and the Status of Female Migrants. San Miniato, Italia, 28-31 de marzo de 1990. Nueva York: United Nations Department for Economic and Social Information and Policy Analysis, Population Division.

BROCHMANN, Grete (1993). Middle East Avenue: female migration from Sri Lanka to the Gulf. Boulder: Westview Press.

CACHÓN, L. (1997). «Notas sobre la segmentación del mercado de trabajo y la segregación sectorial de los inmigrantes en España» Comunicación presentada en el congreso sobre La Inmigración en España, 16-18 de octubre de 1997. Madrid: Instituto Universitario Ortega y Gasset.

CIDOB (1998). La immigració estrangera a Barcelona. L'observatori permanent de la immigració a Barcelona 1994-1997. Barcelona: Ajuntament de Barcelona.

COMISIÓN INTERMINISTERIAL DE EXTRANJERÍA (CIE) (1998). Anuario estadístico de extranjería 1996. Madrid: Ministerio del Interior.

DíEZ, J. (dir.) (1998). Actitudes hacia los inmigrantes. OPI. Madrid: Ministerio de Trabajo y Asuntos Sociales.

ESCRIVÁ, A. (1997). «Control, composition and character of new migration to southwest Europe: the case of Peruvian women in Barcelona». New Community 23(1): 43-57, enero.

- (1999). Mujers peruanas en Barcelona. Tesis de doctorat. Bellaterra: UAB. Departament de Sociologia.

GURAK, D.T.; CACES, F. (1992). «Migration networks and the shaping of migration systems». En KRITZ, M.M.; LIM, L.L.; ZLOTNIK, H. (eds.). International Migration Systems: A Global Approach. Oxford: Clarendon Press.

Hillmann, F. (1996). Jenseits der Kontinente. Migrationsstrategien von Frauen nach Europa. Pfaffenweiler: Centaurus Verlag.

InSTRAW (1994). The migration of women. Methodological issues in the measurement and analysis of internal and international female migration. Nueva York: United Nations.

JELIN, E. (1978). «Migration and labor force participation of Latin American women: the domestic servants in the cities». Signs, v. III, no 3, primavera de 1978, p. 129-141. 
LIM, L.L. (1998). «The analysis of factors generating international migration: the processes generating the migration of women", Technical symposium on international migration and development. The Hague, Holanda, 29 de junio a 3 de julio de 1998, UN-IOM.

LYCKLAMA À NiJEHOLT, G. (1995). «Women in international migration». En HEYZER, N. (ed.). A Commitment to the World's Women. Perspectives on development for Beijing and beyond. Nueva York: Unifem.

Oso, L. (1998). La migración hacia España de mujeres jefas de hogar. Colección Estudios $\mathrm{n}^{\circ}$ 52. Madrid: Instituto de la Mujer.

PérEZ, G. (1997). Inmigración y redes sociales. Tesis doctoral, Departamento de Sociología I, Madrid: Universidad Complutense de Madrid.

PIORE (1975). «Notas para una teoría de la estratificación del mercado de trabajo». En TOHARIA, L. (comp.) (1983). El mercado de trabajo: teorías y aplicaciones. Madrid: Alianza editorial.

Portes, A.; Rubaut, R. (1990). Immigrant America. Berkeley: University of California Press.

Ribas, N. (1994). «Origen del proceso emigratorio de la mujer filipina a Cataluña». Papers, 43: 101-114.

TANSKI, J.R. (1994). «The impact of crisis, stabilization and structural adjustment on women in Lima, Peru». World Development, vol. 22, núm. 11, noviembre: 1627-42.

TORNOS y otros (1997). Los peruanos que vienen. Quiénes son y cómo entienden típicamente la inmigración los inmigrantes peruanos. Madrid: UPCO.

UNITED NaTIONS (UN) (1997). International migration and development. Nueva York: United Nations. 